\title{
Iron-deficiency Anemia in Pregnant Women: What preventing Practitioners from using IV Iron Sucrose
}

\author{
Hema Divakar
}

\section{ABSTRACT}

Background: Severe anemia in pregnancy results in relatively poor maternal and fetal outcome. Maternal effects are preterm labor, preeclampsia, sepsis and postpartum hemorrhage and increase need of blood transfusion. In India, the decision to recommend appropriate supplementation for IDA in pregnant women is left to the health care personnel and based on the individual maternal condition.

Objective: To assess the problems/limitations of health care practitioners to treat IDA with IV iron sucrose in pregnant women and to suggest ways forward for expansion of its use with confidence.

Materials and methods: The questionnaire included 18 questions altogether related to treatment, influencing factors for treatment, risk factors, attitutes and awareness about parenteral iron sucrose supplementation. All data were entered into an electronic database without personal identifiers to maintain confidentiality. The data was analyzed by using SPSS version 17.0.

Results: The survey consisted of responses from 107 health care professionals from urban and rural practitioners in India. Out of $107,28.1 \%$ respondents said that the majority of the anemic patients were between 9.9 and $7.0 \mathrm{mg} / \mathrm{dl} \mathrm{Hb}$-moderate category. A total of $78(72.90 \%)$ said that they would recheck $\mathrm{Hb}$ levels 4 weeks after oral ion treatment for checking the patient's response. Of the respondents, $42.52 \%$ of them said that the women were compliant and took supplementation as per prescription. All respondents agreed that there could be a mean $58 \%$ reduction of blood transfusions by using IV iron sucrose. Many respondents $(74,79.44 \%)$ expressed interest to have more information from recent research to expand the indications for use.

Conclusion: Dissemination of information related to IV iron sucrose to all practitioners and reduction in costs would help them to expand the use with confidence and avert many complications related to maternal and fetal health due to gestational anemia.

Keywords: Routine iron and folic acid supplementation, KAP, Blood transfusion, Preterm labor, IV iron sucrose postpartum hemorrhage.

How to cite this article: Divakar $\mathrm{H}$. Iron-deficiency Anemia in Pregnant Women: What preventing Practitioners from using IV Iron Sucrose. Int J Infertility Fetal Med 2012;3(1): 1-7.

\section{Source of support: Nil}

Conflict of interest: None declared

Date of Received: 30-11-11

Date of Acceptance: 30-11-11

Date of Publication: January 2012

\section{INTRODUCTION}

Iron-deficiency anemia (IDA) is the most common nutritional deficiency problems affecting pregnant women worldwide. ${ }^{1}$ The high prevalence of iron and other micronutrient efficiencies among women during pregnancy in developing countries is of concern and maternal anemia is still a cause of considerable perinatal morbidity and mortality. ${ }^{2}$ Most women begin their pregnancy with partially or completely depleted iron reserves. During pregnancy, there is a greater demand for iron to meet the requirement of red blood cell mass expansion in the mother, fetal and placental blood and blood loss at delivery. ${ }^{3}$ Also, iron deficiency would be exaggerated because of the ability of fetus to extract its requirement in obligatory one way direction even from iron deficient mothers.

Severe anemia in pregnancy results in relatively poor maternal and fetal outcome. Maternal effects are preterm labor, preeclampsia, sepsis and postpartum hemorrhage and increase need of blood transfusion. ${ }^{4}$ Recent study reported a fetal mortality rate of $50 \%$ at 7 months, $28 \%$ at 8 months and $24 \%$ at 9 months of gestation. ${ }^{5}$ Mild to moderate degrees of iron-deficiency anemia can impact motor and mental development in children and adolescents. ${ }^{6,7}$ There is some evidence that iron deficiency without anemia affects cognition in adolescent girls. ${ }^{8}$ Therefore, it is very important to manage gestational anemia before it may lead to far reaching complications in the neonate and infants. International organizations have been campaigning routine iron and folic acid supplementation for every pregnant woman in areas of high anemia prevalence. ${ }^{9,10}$ Apart from maintaining balanced diet, general treatment includes iron supplementation by either oral or intramuscular or intravenous routes. Interventions to control IDA include iron supplementation and iron fortification, health and nutrition education, control of parasitic infections and improvement of sanitation. ${ }^{11}$ Though, the National Nutritional Anemia Control Program (NNACP) in India was launched in 1970, anemia continues to be a major public health problem. The program was unsuccessful due to the lack of effective health education and supervision. ${ }^{12}$ In most developing countries like India, the decision to recommend appropriate supplementation for IDA in pregnant women is left to the health care personnel and is based on the individual maternal condition. ${ }^{13}$ It is known that intravenous iron treated IDA of pregnancy and restored iron stores faster and more effectively than oral iron with no serious adverse reaction 
(SAEs). ${ }^{14}$ Intravenous iron therapy is safe, convenient more effective than intramuscular iron therapy in treatment of iron-deficiency anemia during pregnancy. ${ }^{14}$

Potentially, given the incidence of moderate and severe IDA in pregnancy, there is scope to treat a larger number of women with IV iron sucrose. This study was aimed to assess the problems/limitations of health care practitioners to treat IDA with IV iron sucrose in pregnant women and to suggest ways forward for expansion.

\section{MATERIALS AND METHODS}

An 18 question online survey (www.abcofobg.com) was developed to assess providers' knowledge, practices and attitudes related to understanding and management of IDA. The final sample consisted of 107 respondents. The questionnaire included 18 questions altogether related to treatment, influencing factors for treatment, risk factors and parenteral iron sucrose supplementation. All data were entered into an electronic database without personal identifiers to maintain confidentiality. The data was analyzed by using SPSS version 17.0.

\section{RESULTS}

The survey consisted of responses from 107 health care professionals from urban and rural practitioners in India.

\section{Prevalence}

Out of $107,28.1 \%$ respondents said that the majority of the anemic patients were between 9.9 and $7.0 \mathrm{mg} / \mathrm{dl}$ $\mathrm{Hb}$ - moderate category.

\section{Influencing Factors on a Scale of 1 to 5}

Table 1 summarizes the IDA treatment influencing factors on a scale of 1 to 5 . Safety was ranked no. 1 by $78(72.90 \%)$ respondents, efficacy no. $2(65,60.75 \%)$, compliance no. 3 $(39,36.45 \%)$, ease of administration no. $4(38,35.51 \%)$ and cost was ranked no. 5 by $63(58.88 \%)$ respondents.

\section{Treatment of Iron-deficiency anemia}

Table 2 summarizes the treatment options of IDA. Overall, $73.54 \%$ prescribed oral iron as the first line therapy.

\section{Response to Treatment}

Table 3 summarizes responses in treating of IDA. A total of $78(72.90 \%)$ said that they would recheck $\mathrm{Hb}$ levels 4 weeks after oral ion treatment for checking the patient's response. Overall $82(76.64 \%)$ respondents said that the response to oral iron therapy was moderate $(>1$ to $<2 \mathrm{gm} / \mathrm{dl}$ increase after 4 and 8 weeks).

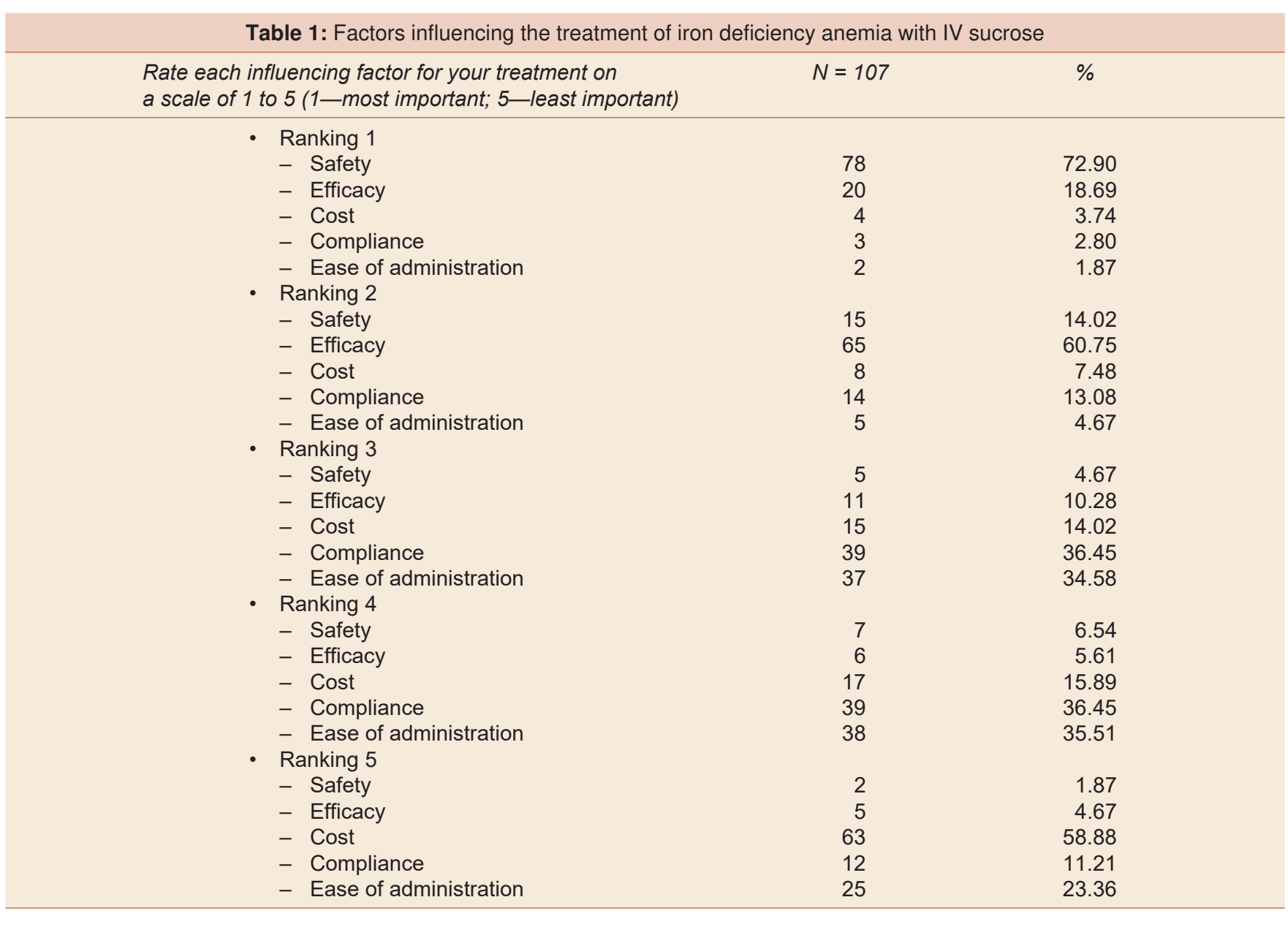




\section{Compliance and Adverse Reactions}

Of the respondents, $42.52 \%$ of them said that the women were compliant and took supplementation as per prescription. The respondents also mentioned that the patients stopped taking oral iron mainly because of gastritis (mean $44.58 \%$ ), constipation (mean $24.75 \%$ ), diarrhea (mean 16.11\%).
Overall, $63.55 \%$ (Table 3 ) respondents agreed that there were adverse reactions (AEs) with oral iron (Fig. 1).

\section{Parenteral Iron}

Table 4 summarizes the methodology of parenteral iron supplementation in IDA patients. Many respondents

Table 2: Practitioners opinion in treating iron deficiency anemia

\begin{tabular}{|c|c|c|}
\hline Treatment of iron-deficiency anemia & $N=107$ & $\%$ \\
\hline - Do your patients have adverse reactions to oral iron? & 68 & 63.55 \\
\hline - Constipation & 58 & 54.21 \\
\hline - Diarrhea & 35 & 32.71 \\
\hline - Gastritis & 60 & 56.07 \\
\hline - Abdominal cramps & 23 & 21.50 \\
\hline - Rashes & 4 & 3.74 \\
\hline - Burning & 11 & 10.28 \\
\hline - Nausea & 50 & 46.73 \\
\hline - Vomiting & 34 & 31.78 \\
\hline - Swelling of feet & 1 & 0.93 \\
\hline - Joint pains & 2 & 1.87 \\
\hline - Chest pain & 1 & 0.93 \\
\hline - Breathlessness & 2 & 1.87 \\
\hline - Giddiness & 6 & 5.61 \\
\hline - Anaphylactic shock & 0 & 0.00 \\
\hline - Do your patients have adverse reactions to parenteral iron? & 48 & 44.86 \\
\hline - Constipation & 5 & 4.67 \\
\hline - Diarrhea & 3 & 2.80 \\
\hline - Gastritis & 2 & 1.87 \\
\hline - Abdominal cramps & 8 & 7.48 \\
\hline - Rashes & 28 & 26.17 \\
\hline - Burning & 11 & 10.28 \\
\hline - Nausea & 12 & 11.21 \\
\hline - Vomiting & 11 & 10.28 \\
\hline - Swelling of feet & 7 & 6.54 \\
\hline - Joint pains & 27 & 25.23 \\
\hline - Chest pain & 9 & 8.41 \\
\hline - Breathlessness & 20 & 18.69 \\
\hline _ Giddiness & 17 & 15.89 \\
\hline - Anaphylactic shock & 20 & 18.69 \\
\hline - Do you know of any preparations, where deaths have not be & & \\
\hline - Jectofer & 20 & 18.69 \\
\hline - Jectofer & 8 & 7.48 \\
\hline - Imferon & 8 & 7.48 \\
\hline - Venofer & 7 & 6.54 \\
\hline - IV iron sucrose & 81 & 75.70 \\
\hline - Other & 12 & 11.21 \\
\hline \multicolumn{3}{|c|}{$\begin{array}{l}\text { Ratio (\%) of anemic antenatal patients in a day of the total antenatal patients, } \\
\text { how many of them are anemic? }\end{array}$} \\
\hline-10 & 12 & 11.22 \\
\hline-20 & 20 & 18.7 \\
\hline-30 & 9 & 8.41 \\
\hline-40 & 18 & 16.82 \\
\hline-50 & 15 & 14.02 \\
\hline-60 & 13 & 12.15 \\
\hline-70 & 8 & 7.48 \\
\hline-80 & 9 & 8.41 \\
\hline-90 & 3 & 2.8 \\
\hline-100 & 0 & 0 \\
\hline \multicolumn{3}{|c|}{ - What percentage of the anemic patients fall in the categories listed below? } \\
\hline$->11$ & 22 & 20.56 \\
\hline$-10.5-11$ & 20 & 18.7 \\
\hline$-0-10.4$ & 21 & 19.63 \\
\hline$-9.9-7$ & 30 & 28.1 \\
\hline$-6.9-4$ & 7 & 6.54 \\
\hline$-<4$ & 7 & 6.54 \\
\hline
\end{tabular}


$(62,57.94 \%)$ used IV iron sucrose for severe anemia when the patient showed intolerance to oral iron. $44.86 \%$ said that there were minor AEs to parenteral iron. Many respondents $(81,75.70 \%)$ agreed that there were no death with IV iron sucrose preparations (Fig. 1).

\section{Reduction in Blood Transfusion Rates}

All respondents agreed that there could be a mean 58\% reduction of blood transfusions by using IV iron sucrose.

\section{Reasons for using IV Iron Sucrose}

As presented in Figure 2, the main reasons to use IV iron sucrose were efficacy $(83,77.57 \%)$, less blood transfusions needed to be done $(79,73.83 \%)$, no AEs $(58,54.21 \%)$.

\section{Reasons for not using IV Iron Sucrose}

The reasons for not using IV iron sucrose more frequently to treat IDA were cost $(69,64.49 \%)$. Many respondents $(74,79.44 \%)$ expressed interest to have more information from recent research to expand the indications for use (Fig. 3 and Table 4).

\section{DISCUSSION}

There are a large number of practitioners - 30\% are seeing moderate anemia in majority of pregnant women indicating that there is a prevalence of moderate category of anemia in a significant number of pregnant Indian women.

To treat anemia in pregnancy, the clinicians ranked safety as top priority $(72.90 \%)$ and cost as a least priority (58.88\%) (Fig. 4). Overall, 73\% of practitioners used oral iron therapy as the first line, even in moderately severe anemia in pregnancy. The method of assessment of the response to oral iron was by rechecking $\mathrm{Hb}$ levels at 4 to 8 weeks, which is a practical and pragmatic method. Though the grade B recommendation states that $2 \mathrm{gm} / \mathrm{dl}$ should be considered as satisfactory response, $76 \%$ of clinicians said that the response was between 1 to $2 \mathrm{gm} / \mathrm{dl}$ which points toward suboptimal response or failed response.

Gastritis, constipation and diarrhea were the main reasons for noncompliance and $48 \%$ of clinicians agreed that there was a lack of compliance and $63 \%$ of the clinicians endorsed that there were AEs when patients are on oral iron

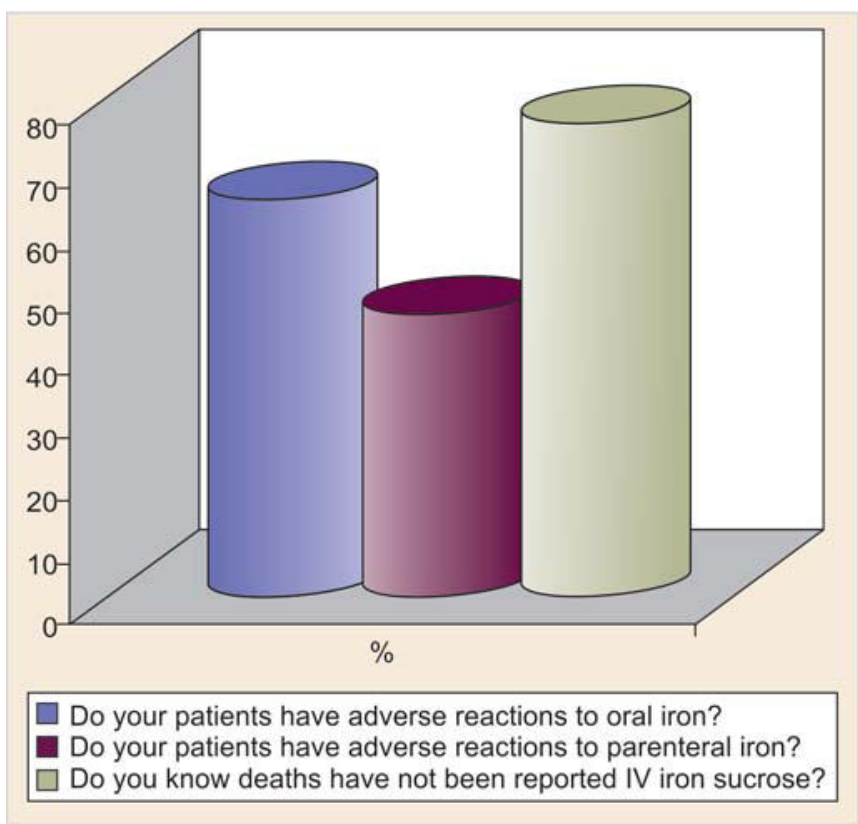

Fig. 1: Treatment of iron-deficiency anemia

Table 3: Risk factors in treating iron deficiency anemia

\begin{tabular}{lrr}
\multicolumn{2}{c}{ Table 3: Risk factors in treating iron deficiency anemia } & N \\
\hline \multicolumn{1}{c}{ Risk factors in treating IDA } & \\
\hline
\end{tabular}




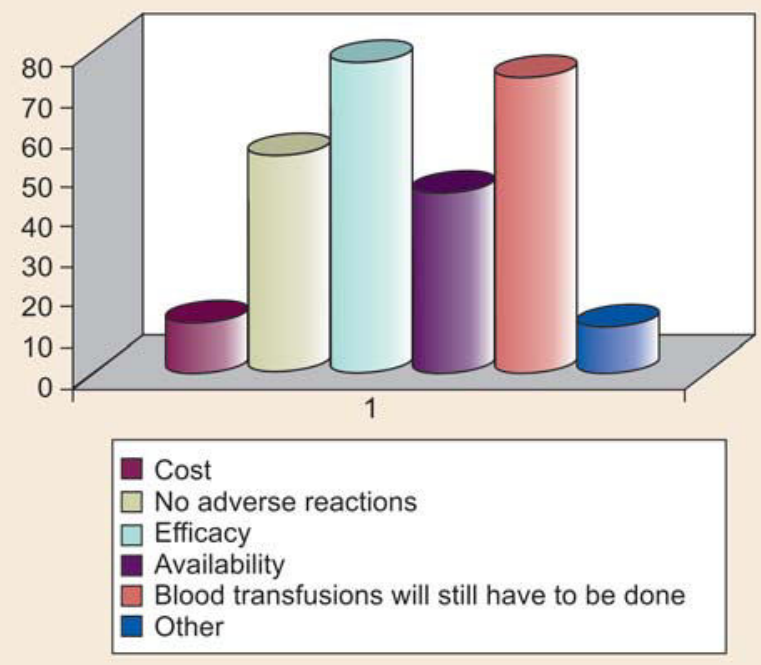

Fig. 2: What are the reasons for using IV iron sucrose to treat IDA?

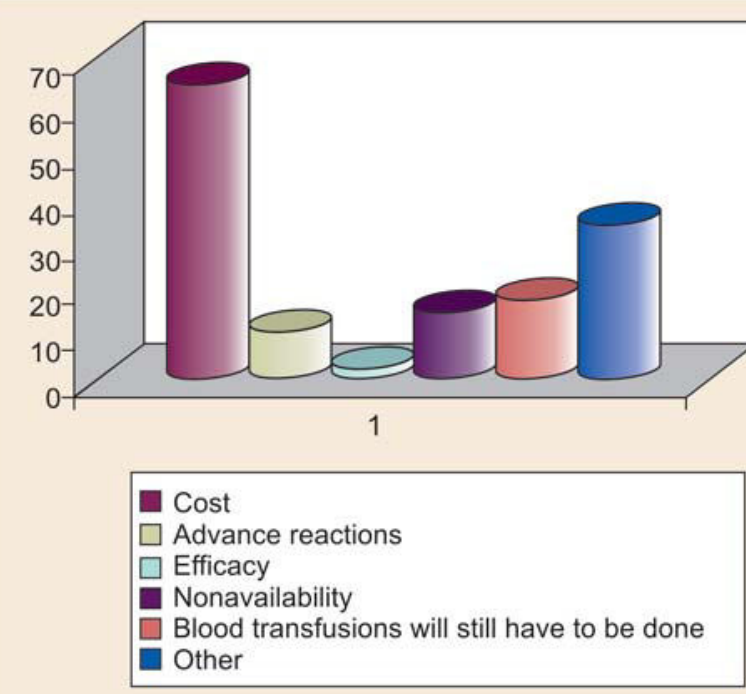

Fig. 3: What are the reasons for not using IV iron sucrose more frequently to treat IDA?

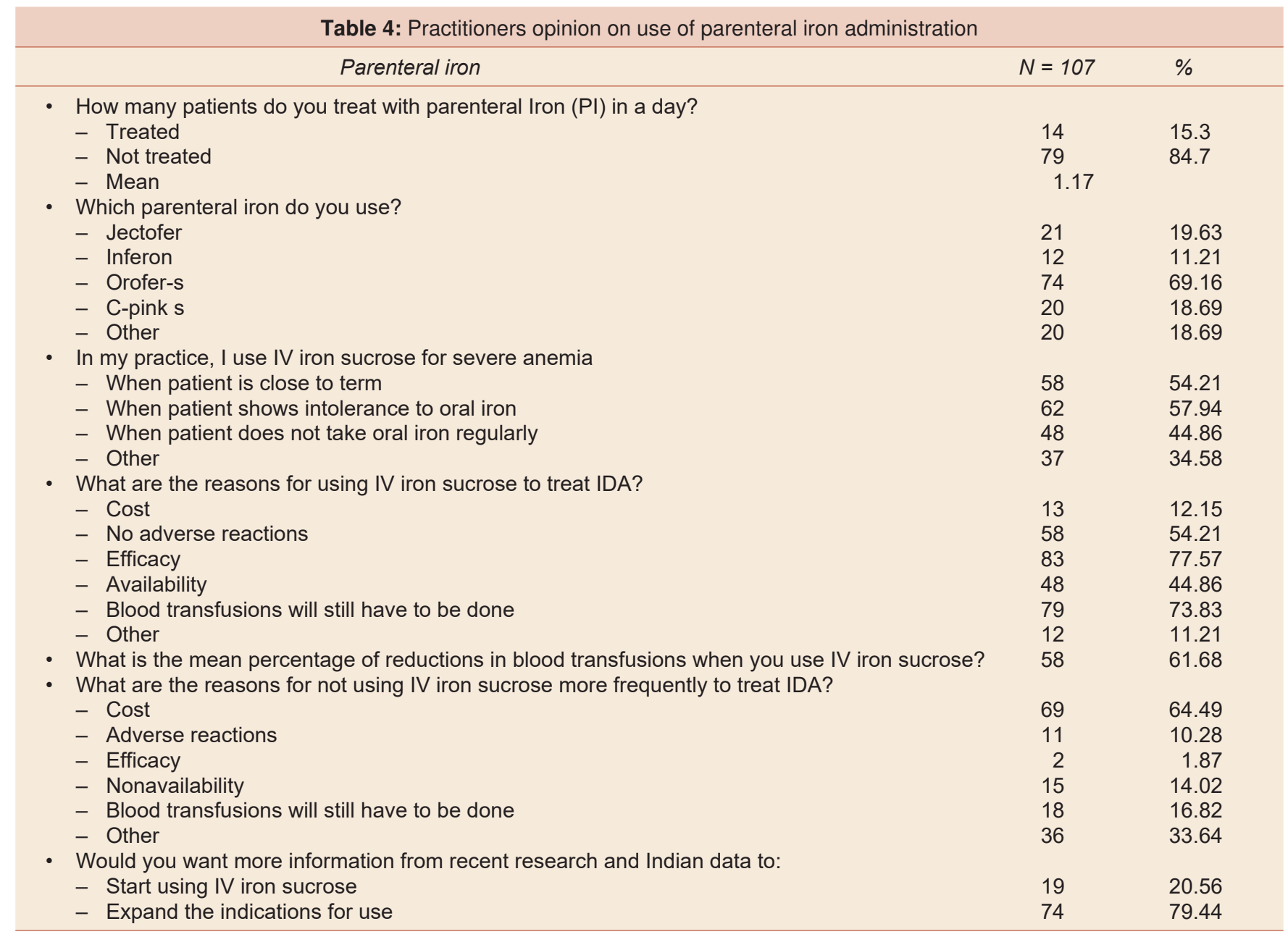

therapy. It is clear to the practitioners themselves that administration of oral iron supplementations is not sufficiently enough in order to reverse anemia promptly, due to the limited absorption, the gastrointestinal symptoms and the poor compliance for long treatment of the patients
(Table 5). Intravenous iron treatment is indicated for patients with poor compliance in oral supplementations, in cases with poor iron absorption (bowel operations or diseases), in patients with severe renal impairment and in postpartum hemorrhage. $^{15,16}$ 


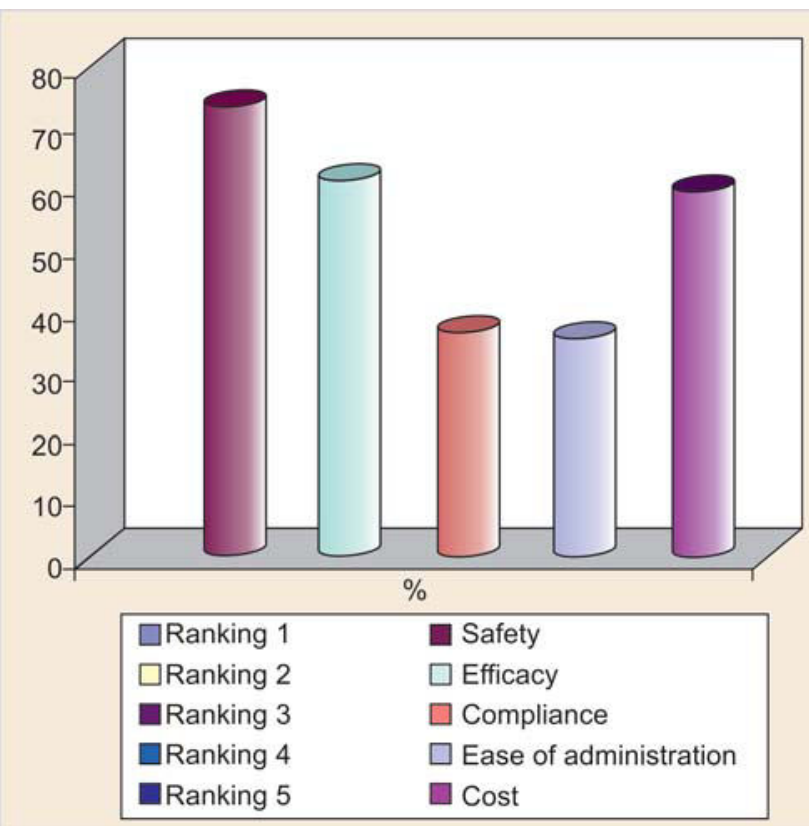

Fig. 4: Influencing factor for your treatment on a scale of 1 to 5 (1-most important; 5-least important)

From the earlier study reports, it is clear that intravenous iron sucrose is safe and effective $e^{17,18}$ in the treatment of iron-deficiency anemia during pregnancy than control group taking oral iron supplements. Intravenous iron sucrose group achieved a significantly higher $\mathrm{Hb}$ level $(128.5 \pm$ $6.6 \mathrm{gm} / 1 \mathrm{vs} 111.4 \pm 12.4 \mathrm{gm} / \mathrm{l} ; \mathrm{p} \leq 0.001)$ in a shorter period $(6.9 \pm 1.8$ weeks vs $14.9 \pm 3.1$ weeks; $\mathrm{p} \leq 0.001) .{ }^{17}$ Also, compared oral with ferrous sulfate, IV iron therapy with an iron sucrose complex significantly increased serum ferritin level within a short time with fewer AEs than oral iron therapy in women with postpartum iron-deficiency anemia. ${ }^{19}$ Despite this information, most practitioners used parenteral IV iron sucrose only in cases of severe anemia $<7 \mathrm{gm} / \mathrm{dl}$. Those who used it agreed that IV iron sucrose was efficacious (77.57\%), safe (54.21\%) and helped to avoid blood transfusions $(73.83 \%)$. Others were not using (64.49\%) it because of its cost (Fig. 3) and require more information on the safety and larger experience for enabling them to use this new molecule with confidence $(80 \%)$.

Most had the experience with the clinical use of iron dextran, especially the large molecular form and faced complications inclusive of anaphylactic reactions and death. ${ }^{20}$ They had the fear of using parenteral iron.

Intravenous iron sucrose tolerance seems to be excellent without AE, in accordance with the literature. ${ }^{21}$ The majority of clinicians had poor knowledge and minimal experience with the use of newer preparations like IV iron sucrose. $80 \%$ of practitioners had little awareness regarding safety related to the treatment of IDA with IV iron sucrose and were hesitant to use it but were eager to know more.

Intravenous iron sucrose could be the Holy Grail in the eradication of IDA in pregnancy in a setting, such as India. The issue of significant cost, especially when the challenge is to deliver this treatment to rural areas where the vast majority of the women requiring the treatment reside, could be a significant barrier. Oral and/or parenteral iron supplementation has failed to eradicate IDA and cannot be said to be cost-effective. While definitive cost-effective

\begin{tabular}{|c|c|c|c|c|}
\hline & Day & IV group $(n=50)$ & $P O$ group $(n=25)$ & $p$-value \\
\hline \multirow[t]{3}{*}{ Erythropoiesis $\mathrm{Hb}(12-16 \mathrm{gm} / \mathrm{dl})$} & 0 & $8.2 \pm 0.6(6.3-9.0)$ & $8.2 \pm 0.5(7.3-8.7)$ & 0.813 \\
\hline & 7 & $10.9 \pm 1.1(9.0-13.5)$ & $11.2 \pm 0.9(10.2-12.5)$ & 0.125 \\
\hline & 28 & $12.5 \pm 1.6(9.5-15.1)$ & $11.8 \pm 0.7(11.0-13.5)$ & 0.200 \\
\hline \multirow[t]{3}{*}{ Hematocrit (36-50\%) } & 0 & $24.9 \pm 2.4(20.5-29.6)$ & $25.1 \pm 2.54(21.7-29.8$ & 0.736 \\
\hline & 7 & $33.8 \pm 3.0(28.3-40.6)$ & $34.7 \pm 3.1(31.2-38.7)$ & 0.349 \\
\hline & 28 & $51.6 \pm 7.2(32.0-42.1)$ & $36.5 \pm 2.0(34.2-40.6)$ & 0.206 \\
\hline \multirow[t]{3}{*}{ MCV (81-99 fl) } & 0 & $76.1 \pm 12.4(52.0-97.0)$ & $70.9 \pm 9(56.0-86.9)$ & $<0.01$ \\
\hline & 7 & $81.6 \pm 9.2(66.1-95.6)$ & $80.1 \pm 2.1(77.1-81.7)$ & 0.155 \\
\hline & 28 & $84.9 \pm 8.8(63.5-95.5)$ & $81.1 \pm 3.6(77.5-90.2)$ & 0.057 \\
\hline \multicolumn{5}{|l|}{ Iron status } \\
\hline \multirow[t]{3}{*}{ Serum iron $(37-145 \mathrm{mg} / \mathrm{dl})$} & 0 & $42.8 \pm 29.3(19.0-159.0)$ & $34.5 \pm 12.4(20.0-54.0)$ & 0.507 \\
\hline & 7 & $72.7 \pm 17.9(27.0-107.0)$ & $67.8 \pm 32.2(27.0-103.0$ & 0.435 \\
\hline & 28 & $86.2 \pm 44.3(18.0-215.0)$ & $73.5 \pm 33.9(45.0-122.0)$ & 0.166 \\
\hline \multirow[t]{3}{*}{ tSIBC (274-497 mg/dl) } & d0 & $411.0 \pm 105.2(35-564)$ & $436.7 \pm 98.1(267-569)$ & $<0.01$ \\
\hline & $\mathrm{d} 7$ & $303.5 \pm 63.8(176-420)$ & $334.2 \pm 28.1(309-374)$ & $<0.01$ \\
\hline & $\mathrm{d} 28$ & $287.2 \pm 89.1(93-459)$ & $299.8 \pm 83.9(229-459$ & $<0.820$ \\
\hline \multirow[t]{3}{*}{ Ferritin (6-159 ng/dl) } & d0 & $26.7 \pm 40.9(1.5-178.0)$ & $9.9 \pm 6.8(4.4-25.0)$ & $<0.05$ \\
\hline & $\mathrm{d} 7$ & $124.0 \pm 122.9(5.9-55.3)$ & $18.6 \pm 9.3(5.9-32.3$ & $<0.001$ \\
\hline & $\mathrm{d} 28$ & $100.0 \pm 79.7(4.3-252.0)$ & $17.4 \pm 14.9(4.3-34.4)$ & $<0.01$ \\
\hline \multirow[t]{3}{*}{ CRP (0-3 mg/l) } & d0 & $4.1 \pm 5.7(0.0-19.0)$ & $2.8 \pm 3.8(0.0-8.5)$ & 0.236 \\
\hline & $\mathrm{d} 7$ & $0.8 \pm 1.6(0.0-4.1)$ & $0.8 \pm 1.3(0.0-2.7)$ & 0.670 \\
\hline & $\mathrm{d} 28$ & $0.1 \pm 0.2(0.0-0.9)$ & $0.1 \pm 0.1(0.0-0.2)$ & 0.626 \\
\hline
\end{tabular}

Values in brackets are the normal range; Hb: Hemoglobin; MCV: Mean cell volume; tSIBC: Total serum iron-binding capacity; CRP: C-reactive protein 
studies for the use of iron sucrose are urgently needed, yet it is difficult to 'cost' the morbidity and mortality suffered by women in the developing world as a result of irondeficiency anemia, never mind the impact on the next generation with regard to impaired motor and intellectual development associated with IDA in the newborn and child.

Costs could be reduced by administering the iron sucrose as a single bolus intravenous push over 5 minutes and by expanding the usage as against blood transfusions. All these potential solutions require rigorous research and evaluation before they could be implemented.

\section{CONCLUSION}

Dissemination of information related to IV iron sucrose to all practitioners and reduction in costs would help them to expand the use with confidence and avert many complications related to maternal and fetal health.

\section{ACKNOWLEDGEMENT}

We extend our sincere thanks to Dr Peter Pothula, BioQuest, for his valuable editorial guidance in the generation of this report.

\section{REFERENCES}

1. Thangaleela T, Vijayalakshmi P. Prevalence of anaemia in pregnancy. Indian J Nutr Diet 1994;31:26-32.

2. Cutner A, Bead R, Harding J. Failed response to treat anaemia in pregnancy: Reasons and evaluation. J Obstet Gynecol 1999;suppl:S23-27.

3. Bothwell Thomas H. Iron requirements in pregnancy and strategies to meet them. Am J Clin Nutr 2000;72:257-64.

4. Bayoumeu F, Subiran-Buisset C, Baka NE, Legagneur H, Monnier-Barbarino P, Laxenaire MC. Iron therapy in irondeficiency anemia in pregnancy: Intravenous route versus oral route. Am J Obstet Gynecol Mar 2002;186(3):518-22.

5. Khan MM. Effects of maternal anemia on fetal parameters. J Ayub Med Coll Abbottabad 2001;13:38-41.

6. Halterman JS, Kaczorowski JM, Aligne CA, Auinger P, Szilagyi PG. Iron deficiency and cognitive achievement among school-aged children and adolescents in the United States. Pediatrics 2001;107:1381-86.

7. Algarin C, Peirano P, Garrido M, Pizarro F, Lozoff B. Irondeficiency anemia in infancy: Long-lasting effects on auditory and visual system functioning. Pediatr Res 2003;53:217-23.

8. Verdon F, Burnand B, Stubi CL, Bonard C, Graff M, Michaud A, et al. Iron supplementation for unexplained fatigue in non-anaemic women: Double blind randomised placebo controlled trial. BMJ 2003;326:1124.
9. Beard J. Effectiveness and strategies of iron supplementation during pregnancy. American Journal of Clinical Nutrition 2000;71:1288-94.

10. Villar J, Merialdi M, Gulmezoglu AM, Abalos E, Carroli G, Kulier R, et al. Nutritional interventions during pregnancy for the prevention or treatment of maternal morbidity and preterm delivery: An overview of randomized controlled trials. Journal of Nutrition 2003;5:1606-25.

11. International Anemia Consultative Group (INACG). Why is iron important and what to do about it?: A new perspective. Report of the 2001 INACG Symposium; Feb 2001, 15-16; Hanoi, Vietnam 2002;1-50.

12. Vijayaraghavan K, Brahmam GNV, Nair KM, Akbar D, Rao Pralhad N. Evaluation of national nutritional anemia prophylaxis programme. Indian J Pediatr 1990;57:183-90.

13. Centers for disease control and prevention. Recommendations to prevent and control iron deficiency in the United States. Morbidity and mortality weekly report 1998;47(RR-3):1-29.

14. Al RA, Unlubilgin E, Kandemir O, Yalvac S, Cakir L, Haberal A. Intravenous versus oral iron for treatment of anemia in pregnancy: A randomized trial. Obstet Gynecol 2005;106: 1335-40.

15. Breymann C. Treatment of iron deficiency anaemia in pregnancy and postpartum with special focus on intravenous iron sucrose complex. J Med Assoc Thai 2005;88:108-09.

16. Gravier A, Descargues G, Marpeau L. Comment eviter les transfusions dans le post-partum interetd unesupplementation martiale par voie intraveineuse. J Gynecol Obstet Biol Reprod 1999;28:77-78.

17. Al-Momen AK, Al-Meshari A, Al-Naaim L. Intravenous iron sucrose complex in the treatment of iron-deficiency anemia during pregnancy. Eur J Obstet Gynecol Reprod Biol 1996;69: 121-24.

18. Giannoulis C, Daniilidis A, Tantanasis T, Dinas K, Tzafettas J. Intravenous administration of iron sucrose for treating anemia in postpartum women. Hippokratia 2009;13(1):38-40.

19. Dede A, Uygur D, Yilmaz B, Mungan T, Uğur M. Intravenous iron sucrose complex vs oral ferrous sulfate for postpartum irondeficiency anemia. International Journal of Gynecology and Obstetrics 2005;90:238-39.

20. Kalkidan Bishu, Agarwal Rajiv. Acute injury with intravenous iron and concerns regarding long-term safety. Clin J Am Soc Nephrol 2006, 1:S19-23.

21. Faich G, Strobos J. Sodium ferric gluconate complex in sucrose: Safer intravenous iron therapy than iron dextrans. Am J Kidney Dis 1999;33:464-70.

\section{ABOUT THE AUTHOR}

\section{Hema Divakar (Corresponding Author)}

Consultant, Department of Obstetrics and Gynecology Divakars Specialty Hospital, Bengaluru, Karnataka, India e-mail: hema_divakar@yahoo.com 